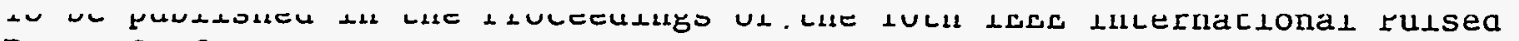

Power Conference, July 10- 13, 1995, Albuquerque, NM.

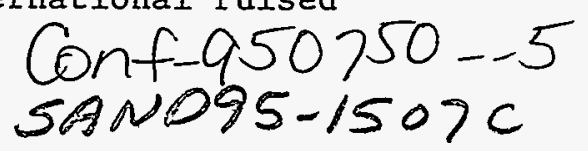

\title{
PHOTOCONDUCTIVE SEMICONDUCTOR SWITCHES FOR FIRING SETS AND ELECTRO-OPTIC MODULATORS*
}

\author{
G. M. Loubriel ${ }^{\dagger}$, F. J. Zutavern ${ }^{\dagger}$, A. G. Baca ${ }^{\ddagger}$, H. P. Hjalmarson ${ }^{\ddagger}$, W. D. Helgeson ${ }^{\dagger}$, and M. W. O'Malley ${ }^{\dagger}$ \\ ${ }^{\dagger}$ High Power Electromagnetics and ${ }^{\ddagger}$ Compound Semiconductor Technology Departments \\ Sandia National Laboratories \\ Albuquerque, NM 87185-1153 \\ Tel. (505)-845-7096 \\ JUL 181955 \\ $08 \pi$
}

Abstract: Optically activated GaAs switches operated in their high gain mode are being used or tested for pulsed power applications as diverse as low impedance, high current pulsers, and high impedance, low current Pockels cell or $\mathrm{Q}$ switch drivers. These are important to firing sets in munitions, lasers used in detonation of munitions, and lasers used in large weapons effects simulators (such as Jupiter). For firing sets we have switched $2.8 \mathrm{kA}$ at $3 \mathrm{kV}$ dc charge in a very compact package. For driving $\mathrm{Q}$ switches, the load is the small $(30 \mathrm{pF})$ capacitance of the $\mathrm{Q}$ switch which is charged to $6 \mathrm{kV}$. We have demonstrated that we can modulate a laser beam with a sub ns risetime. Some aspects of the switches that are relevant to most of these applications are lifetime (longevity), leakage resistance, jitter, and trigger energy. This paper will describe the specific project requirements and switch parameters in all of these applications, and emphasize the switch research and development that is being pursued to address the important issues.

\section{Introduction: General Switch Results}

Our research has focused on optically triggered, high gain GaAs photoconductive semiconductor switches (PCSS) for high speed, high power, high voltage electronics and optoelectronics. PCSS offer improvements over existing pulsed power technology. The most significant are: 100 ps risetime, kilohertz (continuous) and megahertz (burst) repetition rates, scalable or stackable to hundreds of kilovolts and tens of kiloamps, optical control and isolation, and the promise of solid state reliability. The switching properties that have been achieved with our lateral $\mathrm{Si}$ (in the linear mode ${ }^{1}$ ) and $\mathrm{GaAs}$ (in the non-linear, high gain switching mode ${ }^{2,3}$ ) are summarized in previous papers. In this paper, we present results which demonstrate recent improvements in GaAs switching. The PCSS are being tested for use in applications such as: ultrawideband (UWB) transmitters, firing sets, electro-optic modulators, current interrupters, and pulsed power applications such as MV accelerators that operate at high repetition rates. Each of these applications imposes a different set of requirements on switch properties. Table I shows the best results obtained with the switches for these applications. The results are not simultaneous.

\begin{tabular}{|l|c|c|c|}
\hline \multicolumn{1}{|c|}{$\begin{array}{c}\text { Table I } \\
\text { Parameter }\end{array}$} & $\begin{array}{c}\text { Si, linear mode, } \\
\text { best individual results. }\end{array}$ & $\begin{array}{c}\text { GaAs, high gain mode, } \\
\text { best individual results. }\end{array}$ & $\begin{array}{c}\text { GaAs, high gain mode, } \\
\text { simultaneous results. }\end{array}$ \\
\hline Switch Voltage (kV) & 123 & 155 & 100 \\
\hline Switch Current (kA) & 3 & 5.2 & 1.26 \\
\hline Peak Power (MW) & 65 & 120 & 48 \\
\hline Rise time (ps) & 200 & 430 & 430 \\
\hline R-M-S jitter (ps) & 0 & 150 & 150 \\
\hline Optical Trigger Energy (nJ) & $>100,000$ & 90 & 180 \\
\hline Optical Trigger Gain & 1 & $10^{5}$ & $10^{5}$ \\
\hline Repetition Rate (Hz) & 540 & 1,000 & 1,000 \\
\hline Electric Field (kV/cm) & 82 & 100 & 67 \\
\hline Device Lifetime (\# pulses) & $1 \times 10^{7}$ & $6 \times 10^{6}$ & $5 \times 10^{4}$, (at 77 kV) \\
\hline
\end{tabular}

Table I. Results of tests with $\mathrm{Si}$ in the linear mode (no gain) and with high gain GaAs switches. The results for $\mathrm{Si}$ and the first GaAs column describe the best individual results for each parameter and are not simultaneous. The last column describes the result of a single experiment.

*This work was supported by the U. S. Department of Energy under Contract DE-AC04-94AL85000. The authors thank M. T. Buttram, M. J. DeSpain, R. A. Hamil, C. H. Sifford, P. A. Smith, and J. H. Weinlein for their help. 
The GaAs switches used in this experiment are lateral switches (see figure 1). We use undoped GaAs of high resistivity $>10^{7} \Omega$-cm. At electric fields below $4 \mathrm{kV} / \mathrm{cm}$, the GaAs switches are activated by the creation of, at most, one electron hole pair per photon absorbed. This linear mode demands high laser power, and after the light is extinguished, the carrier density decays exponentially in 1- 10 ns. At higher electric fields these switches behave very differently. ${ }^{3}$ On triggering, the high field induces carrier multiplication so that the amount of light required is reduced by as much as five orders of magnitude. ${ }^{4}$ We have used trigger energies as low as $180 \mathrm{~nJ}$ to deliver $48 \mathrm{MW}$ in a 30-50 $\Omega$ system. ${ }^{5}$ In the "on" state the field across the switch stabilizes to a constant called the lock-on field. The switch current is circuit-limited provided the circuit maintains the lock-on field. As the initial (prior to triggering) field increases, the switch risetime decreases and the trigger energy is reduced. During high gain switching the switches emit bandgap radiation due to carrier recombination. When this radiation is imaged, filaments are observed, even if the triggering radiation is uniform. ${ }^{6,7}$ The filaments have current densities of several $\mathrm{MA} / \mathrm{cm}^{2}$ and diameters of $15-300 \mu \mathrm{m}$. The work in this field has been presented at various conferences. ${ }^{2}$

\section{High Current. Compact Laser, and High Off Resistance}

Conventional high current firing sets are complex, demanding systems consisting of a power supply, high voltage capacitor, high voltage vacuum tube switch, and resistive detonator or bridge which launches a flyer at high velocity. The system requirements on the high voltage switch demand precise timing, small volume, high voltage, high current, and very low inductance to produce fast current risetimes with a sub- $\Omega$ load. PCSS are being developed for firing sets because of their extremely fast switching and small physical volume and because they utilize standard semiconductor processing techniques. The specific system that we have tested consists of a $120 \mathrm{nF}$ ceramic capacitor which is discharged through the switch into a $0.25 \Omega$ load. The capacitor is either dc or pulse charged to $3 \mathrm{kV}$. When the switch is triggered, the current waveform must have a risetime of $<30$ ns with a peak current of $3 \mathrm{kA}$. Although this circuit seems to be a simple RC circuit, stray inductance and the inductance in the capacitor and switch are large enough to affect the waveform. In practice the system's inductance determines the risetime and peak value of the current waveform.

The most important demands of the firing set application are: high current, low inductance, high dc voltage standoff, high resistance prior to switching, and small size (including the trigger laser).

We first demonstrated low inductance, high current switching with a pulse-charged capacitor. This is shown in figure 2. The current waveform peaks at $2.9 \mathrm{kA}$ (for a charge voltage of $3 \mathrm{kV}$ ), with a risetime of $27 \mathrm{~ns}$. The switches that we used for this demonstration were $\mathrm{n}-\mathrm{i}-\mathrm{n}$, with $\mathrm{Ni}-\mathrm{Ge}-\mathrm{Au}-\mathrm{Ni}$-Au metallization for each of the $\mathrm{n}$ contacts. Their insulating region separating the two contacts was $0.5 \mathrm{~mm}$ (the active length), the total contact width was $5.0 \mathrm{~mm}$. Because of high electric fields the switches were immersed in a dielectric liquid (Fluorinert( $)$ ). Pulse charging of this configuration was required because the resistance across the switch, prior to switching, (the "off resistance") was about $1 \mathrm{M} \Omega$. Also, continued bias at high voltage results in heating and further reductions of the resistance. For this test, a laser diode array was used to trigger the switch. The array consisted of three laser diodes coupled to a $400 \mu \mathrm{m}$ fiber optic. The array delivered $1.6 \mu \mathrm{J}$ in $27 \mathrm{~ns}$ at $808 \mathrm{~nm}$ to illuminate the switch. The circuit that powered this laser was not optimized for size. It occupied an area of about $5 \mathrm{~cm}$ by $5 \mathrm{~cm}$ and required a $40 \mathrm{~V}$ trigger and a $400 \mathrm{~V}$ supply.

To demonstrate that the laser diode array electronics could be made considerably smaller we developed a compact driver that consisted of a ceramic capacitor $(4.7 \mathrm{nF})$ and an avalanche transistor coupled to a similar laser diode array. The trigger voltage was reduced to $5 \mathrm{~V}$. The overall size was $4 \times 8 \times 1 \mathrm{~mm}^{3}$ with a wavelength of 880 $\mathrm{nm}$ and an energy of $1.36 \mu \mathrm{J}$. The optical waveform is shown in figure 3 . The pulse width was $19 \mathrm{~ns}$, with a risetime of about $6 \mathrm{~ns}$. The pulse width was reduced because the GaAs carrier lifetime is about $10 \mathrm{~ns}$. This laser diode array was also used to reproduce the waveform in figure 2. In this case, however, the laser illuminated the switch directly without the use of a fiber optic. The switch was pulse charged.

An important system requirement for the switch is an off resistance greater than $100 \mathrm{M} \Omega$. High off resistance allows dc charging of the switch and reduces leakage current, thereby reducing system size and complexity, and increasing safety. By suitable redesign of the switches, changing the dielectric liquid that surrounds the switch, and passivating the surfaces, resistances as high as $5 \mathrm{G} \Omega$ were obtained. The switches used to achieve high off resistance were $\mathrm{p}-\mathrm{i}-\mathrm{n}$ switches with $\mathrm{Ge}-\mathrm{Au}-\mathrm{Ni}-\mathrm{Au}$ for the $\mathrm{n}$ contact and $\mathrm{Au}-\mathrm{Be}$ for the $\mathrm{p}$ contact. The switches were tested with reverse bias (dc). Figures 4 and 5 show the effect of passivation on the resistance vs. voltage curve. Figure 4 shows data for switches with an insulating region that was $1 \mathrm{~mm}$ long and $5 \mathrm{~mm}$ wide. The passivated switch had high resistance at dc voltages as high as $3 \mathrm{kV}(250 \mathrm{M} \Omega$ at $3 \mathrm{kV})$. Figure 5 shows similar results with switches that were $0.5 \mathrm{~mm}$ long and $2.5 \mathrm{~mm}$ wide. The resistance of the passivated switch was $140 \mathrm{M} \Omega$ 


\section{DISCLAIMER}

This report was prepared as an account of work sponsored by an agency of the United States Government. Neither the United States Government nor any agency thereof, nor any of their employees, makes any warranty, express or implied, or assumes any legal liability or responsibility for the accuracy, completeness, or usefulness of any information, apparatus, product, or process disclosed, or represents that its use would not infringe privately owned rights. Reference herein to any specific commercial product, process, or service by trade name, trademark, manufacturer, or otherwise does not necessarily constitute or imply its endorsement, recommendation, or favoring by the United States Government or any agency thereof. The views and opinions of authors expressed herein do not necessarily state or reflect those of the United States Government or any agency thereof. 


\section{DISCLAIMER}

Portions of this document may be illegible in electronic image products. Images are produced from the best available original document. 
at $3 \mathrm{kV}$ and for the unpassivated switch the resistance is down to $5.7 \mathrm{M} \Omega$ when tests were stopped at $2 \mathrm{kV}$. This shows that it is the surface leakage that was causing the low resistance for the unpassivated switches.

Switches were then operated at high dc voltage. The current waveform is shown in figure 6 . The $\mathrm{p}-\mathrm{i}-\mathrm{n}$ switch used was a $0.5 \mathrm{~mm}$ long by $2.5 \mathrm{~mm}$ wide. The switch was reverse biased, dc charged to $3 \mathrm{kV}$, and triggered with the fiber optic coupled array. The peak current was about $2.7 \mathrm{kA}$ with a risetime of $21 \mathrm{~ns}$. The volume of this system, including the laser diode driver discussed above, was about $40 \mathrm{~mm}^{3}$ and the cost was of the order of $\$ 200$. Cost and volume trends over time for similar devices operated under similar conditions are is shown in figure 7.

\section{Multiple Pulses, Damage Mechanism, and High Gain Mechanism}

It is also a goal to investigate what is required to obtain multiple pulses. In the data of the previous section, the switch was either destroyed during the switching action or was rendered useless because its resistance became too low. Figure 8 shows the current pulses on two consecutive pulses on the same switch. The first pulse achieved a peak current of $2.65 \mathrm{kA}$, the second peaked at $2.3 \mathrm{kA}$. For this test we used a $1.0 \mathrm{~mm}$ long by $5 \mathrm{~mm}$ wide switch to distribute the current. We can also use two switches in parallel, as shown in figure 9 . With only one $0.5 \mathrm{~mm}$ long by $1 \mathrm{~mm}$ wide switch the peak current is about $1.4 \mathrm{kA}$. Using two switches (of the same size) in parallel, a peak current of $2.4 \mathrm{kA}$ was recorded and reduced damage.

To understand the switch damage we measured the switch voltage and the switch current for a $0.5 \mathrm{~mm}$ long - by $5 \mathrm{~mm}$ wide $\mathrm{n}-\mathrm{i}-\mathrm{n}$ switch. The switch was pulsed charged to $3 \mathrm{kV}$ and triggered with the fiber optic coupled laser. The current waveform was that shown in figure 2. The switch voltage is shown in figure 10 . It starts at about $3 \mathrm{kV}$, and after switching drops to close to the expected value of $300 \mathrm{~V}$. From previous tests at low current, we expected the switch voltage to be relatively constant in time and equal to a lock-on field of about $6 \mathrm{kV} / \mathrm{cm}$ times the switch length which in this case it is $0.05 \mathrm{~cm}$. What was surprising is that the switch voltage then rises to about $600 \mathrm{~V}$ and then falls, approaching $100 \mathrm{~V}$. The power dissipated in the switch is shown in figure 11 . It reaches $1.6 \mathrm{MW}$. The total energy deposited on the switch was $0.12 \mathrm{~J}$ out of an initial energy of $0.54 \mathrm{~J}$. This switch lasted only one pulse. The current in the switch was filamentary. The best estimate of the filament size under these conditions is $200 \mu \mathrm{m}$ diameter and $0.05 \mathrm{~cm}$ long. If $0.12 \mathrm{~J}$ is deposited in such a volume of $\mathrm{GaAs}$ the temperature rise is just over 1,000 C. This value is close to the melting point of $\mathrm{GaAs}$ which is $1238 \mathrm{C}$. The damage mechanism may be melting of the GaAs. A more accurate, direct measurement of the temperature is being planned.

An important result is that the voltage across the GaAs switch was not constant even at a few tens of nanoseconds after switching when the filament temperature was probably low. Since the discovery of the high gain effect ${ }^{3}$, all experiments that recorded the switch voltage for times longer than 30 ns have seen a relatively constant voltage. The difference here could be due to many factors related to, and made noticeable by the high current. One possibility for the change could be a small contact resistance. In similar switches we have tried to measure the contact resistance (at low voltage, in the linear mode) by illuminating the insulating region with high laser fluence to reduce its resistance below the contact resistance. Those experiments are very difficult but preliminary results have shown resistances as high as $2 \Omega$. At high current, the voltage drop across a small contact resistance would add to the switch voltage drop. If the contact is heated, and the resistance drops, the voltage would be reduced. Qualitatively, that is what we observe. Another reason for why we do not see a constant voltage relates to a theory of high gain switching ${ }^{8}$ that result in an S-shaped I-V curve. That is, that an $\mathrm{S}$ shape describes the current (ordinate)voltage (abscissa) curve. Because most of the previous experiments had been carried out at impedances of $50 \Omega$, perhaps only a small subset of the S-shaped curve (the vertical part) had been measured. In that part the current rises but the voltage is constant. By increasing the current one can move to the top part of the $S$ shape where both voltage and current are varying. A final possibility is that this result was obtained with low laser energy, as compared to most previous results at higher energy with flashlamp pumped lasers. Experiments to understand the variation in switch voltage as a function of current are being pursued.'

High Gain GaAs for Electro-Optic Modulators

An important application of high gain PCSS is in the production of fast voltage risetimes that control an electro-optic modulator such as a Pockels cell or a Q-switch. In this experiment we have placed a Pockels cell in the output of a Nd:YAG (1064 nm) laser. The laser pulse has a duration of about $30 \mathrm{~ns}$. We want to demonstrate electro-optic modulation by allowing only half of the laser pulse to be transmitted. The crucial parameter is the risetime of the off to on transition which we want to reduce to below one nanosecond. Electrically, the Pockels cell is a capacitor of about $30 \mathrm{pF}$. The circuit (figure 12) we implemented charges this capacitance and keeps it charged while the first part of the laser pulse enters the Pockels cell. Then the high gain PCSS is activated and the switch shorts the capacitance of the Pockels cell. The current risetime determines the risetime or falltime of the optical transition. Figures 13 shows the current and figure 14 the optical signal with a risetime of 600 ps. 
Summary

For the firing set application, we have achieved a reduction in the size of the switch, laser diode array, and laser diode array driver by two orders of magnitude; increased the off resistance of the switch (to reduce leakage prior to laser activation) from $1 \mathrm{M} \Omega$ to $>100 \mathrm{M} \Omega$; eliminated the need to pulse charge the switches and used a dc charge ( $3 \mathrm{kV})$; and studied the issues in achieving multiple shots with a single switch, having obtained two pulses that meet the specifications. Because of these improvements PCSS was demonstrated to be a practical switch technology capable of meeting the goal of delivering $3 \mathrm{kA}$ into the detonator load from a $0.120 \mu \mathrm{F}$ capacitor charged to $3 \mathrm{kV}$. The switch voltage was not constant after switching and the implications of this are being pursued. For the electro-optic modulator, we have shown that the switch can control a Pockels cell producing sub-ns optical risetimes. References

[1] Picosecond Optoelectronic Devices, edited by C. H. Lee (Academic Press, New York, 1984), and High Power Optically Activated Solid State Switches, edited by A. Rosen and F. J. Zutavern (Artech House, Boston, 1993).

[2] See Proceedings from: 6-9th IEEE Pulsed Power Conf., 1987, 1989, 1991, 1993; 18-21st IEEE Power Modulator Symposium, 1988, 1990, 1992, 1994; SPIE Optically Activated Switching I-IV, (vol. 1378, 1632, 1873, 2343), 1990, 1992, 1993, 1994; and IEEE Trans. Elec. Devices, (vol. 37, 38), 1990, 1992.

[3] First reported in: G. M. Loubriel, M. W. O'Malley, and F. J. Zutavern, "Toward Pulsed Power Uses for Photoconductive Semiconductor Switches: Closing Switches," Proc. 6th IEEE Pulsed Power Conference, P. J. Turchi and B. H. Bernstein, eds., Arlington, VA, 1987, p. 145.

[4] F. J. Zutavern and G. M. Loubriel, "High Voltage Lateral Switches from Silicon or GaAs, in High-Power Optically Activated Solid- State Switches, A. Rosen and F. J. Zutavern, Eds., Artech House, Boston, 1993, p. 245.

[5] G. M. Loubriel, F. J. Zutavern, M. W. OMalley, and W. D. Helgeson, "High Gain GaAs Photoconductive Semiconductor Switches for Impulse Sources," Proc. of SPIE Optically Activated Switching Conference IV, SPIE Proc. Series Vol. 2343, W. R. Donaldson, ed., Boston, MA, October 31-November 4, 1994, pp. 180- 186.

[6] R. A. Falk, J. C. Adams, and G. L. Bohnhoff-Hlavlacek, "Optical Probe Techniques for Avalanching Photoconductors," Proc. 8th IEEE Pulsed Power Conf., R. White and K. R. Prestwich, eds., San Diego, CA, 1991, p. 29.

[7] F. J. Zutavern, G. M. Loubriel, M. W. O'Malley, W. D. Helgeson, and D. L. McLaughlin, "High Gain PCSS," Proc. 8th IEEE Pulsed Power Conference, R. White and K. R. Prestwich, eds., San Diego, CA, 1991, p. 23.

[8] H. P. Hjalmarson, F. J. Zutavern, G. M. Loubriel, M. T. Buttram, A. G. Baca, and L. A. Romero, "Thermal Ionization Model for the Sustaining Phase of Lock-on in GaAs", Proc. SPIE Optically Activated Switching Conf. III, SPIE Proc. Series Vol. 1873, R. A. Falk, ed., Los Angeles, CA., January 21-22, 1993, p. 117.

[9] N. C. Anderson at British Aerospace, Bristol, England and the PCSS group at Sandia National Laboratories.

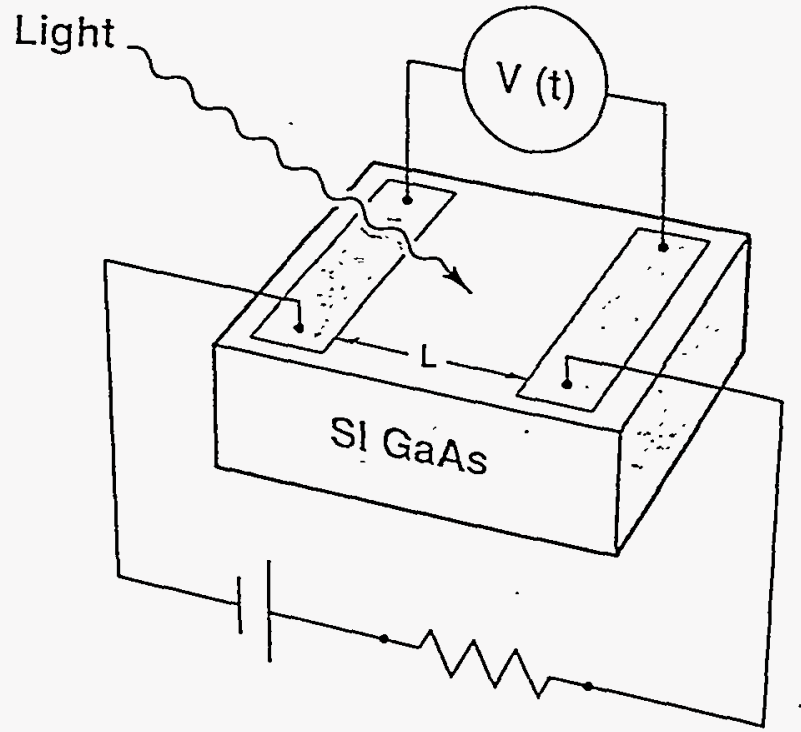

Figure 1. Schematic of the lateral switches used in this study. In the circuit a ceramic capacitor, $120 \mathrm{nF}$, is discharged through the switch to a $0.25 \Omega$ load in a low inductance configuration.

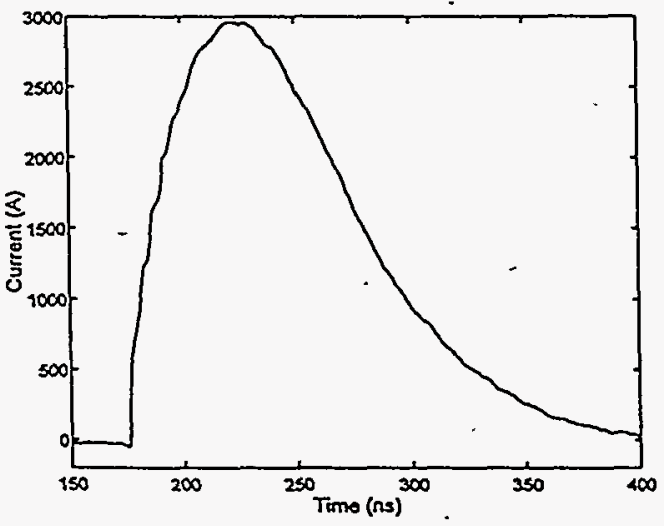

Figure 2. The current waveform for a $0.5 \times 5 \mathrm{~mm}^{2} \mathrm{n}-\mathrm{i}$ n switch triggered with a fiber-coupled laser diode array $(808 \mathrm{~nm}, 1.6 \mu \mathrm{J})$. The capacitor was pulse charged to $3 \mathrm{kV}$. The peak current is $2.9 \mathrm{kA}$, the risetime is $27 \mathrm{~ns}$. 


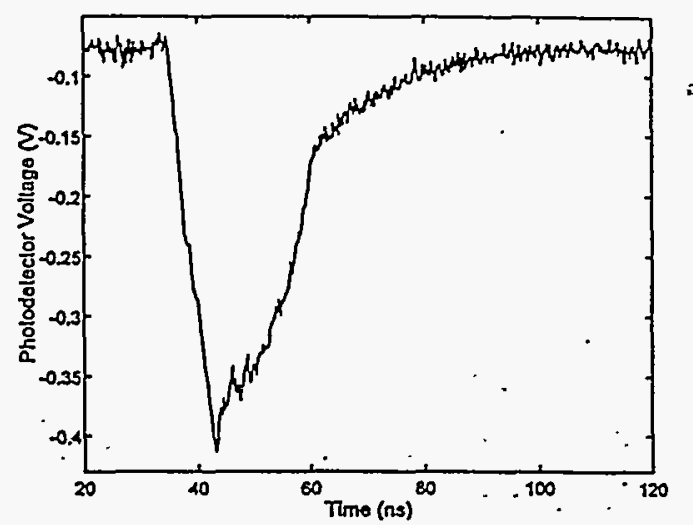

Figure 3. Optical waveform from compact laser. The total energy is $1.36 \mu \mathrm{J}$ at $880 \mathrm{~nm}$. The width is $19 \mathrm{~ns}$ and the risetime is about $6 \mathrm{~ns}$.

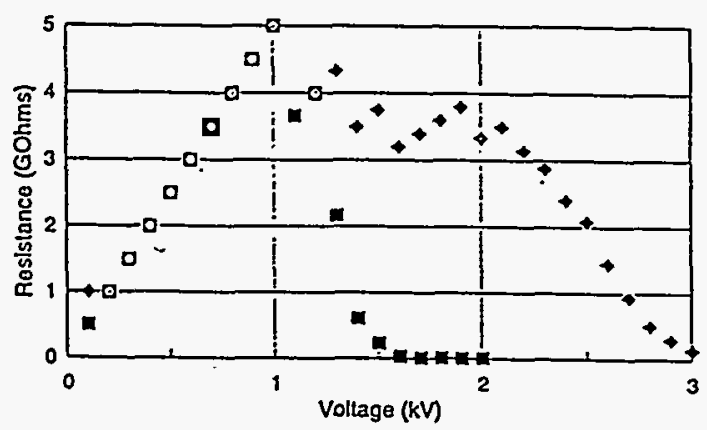

Figure 5. Resistance $(\mathrm{G} \Omega)$ versus voltage $(\mathrm{kV})$ for 0.5 $2.5 \mathrm{~mm}^{2}$ switches with ( $\downarrow$ ) and without ( $\mathbf{m}$ ) passivation. Where the and coincide, a $\square$ is drawn. The voltage is applied dc and the current is measured after 10 seconds. Passivation shifts the transition from high $(G \Omega)$ resistance to sub-G $\Omega$ by $1 \mathrm{kV}$.

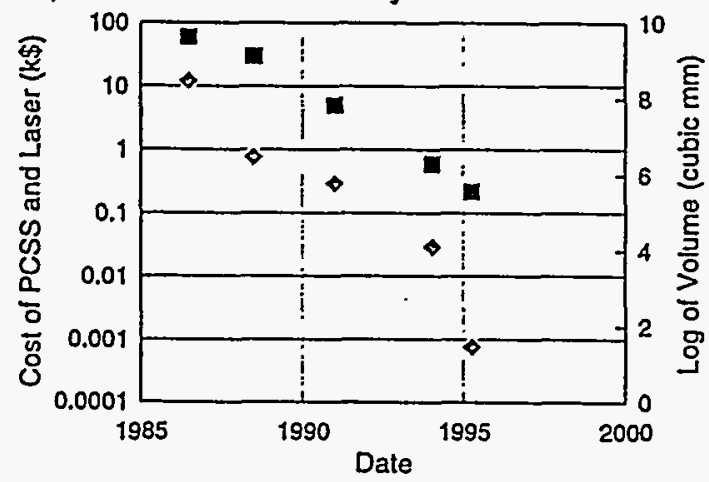

Figure 7. Historical plot of the cost $(\boldsymbol{m}$, in $k \$)$ and volume $\left(\downarrow\right.$, in $\left.\mathrm{mm}^{3}\right)$ of the laser/switch package required to switch firing set type currents. The first two data pairs utilized large flashlamp lasers with the switch in the linear and high gain modes. The third data pair is the demonstration with high gain and laser diode illumination. The fourth utilized spot triggering. The last data pair is described in this paper.

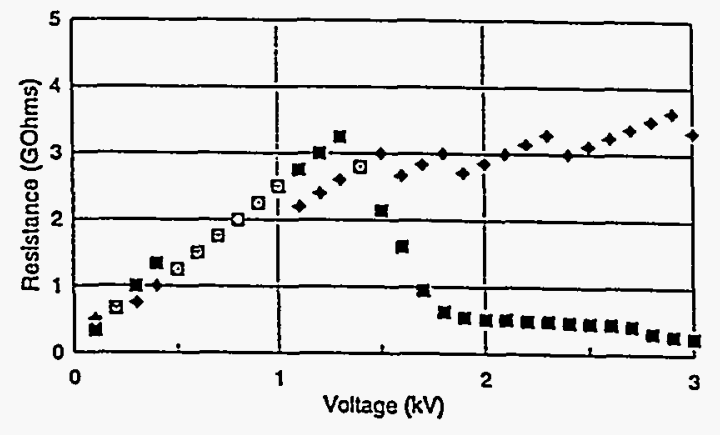

Figure 4. Resistance versus voltage for $1 \mathrm{~mm}$ by $5 \mathrm{~mm}$ switches with $(\triangleleft)$ and without $(\square)$ passivation. Where the and $\square$ coincide, a $\square$ is drawn. The voltage is applied $\mathrm{dc}$ and the current is measured after 10 seconds.

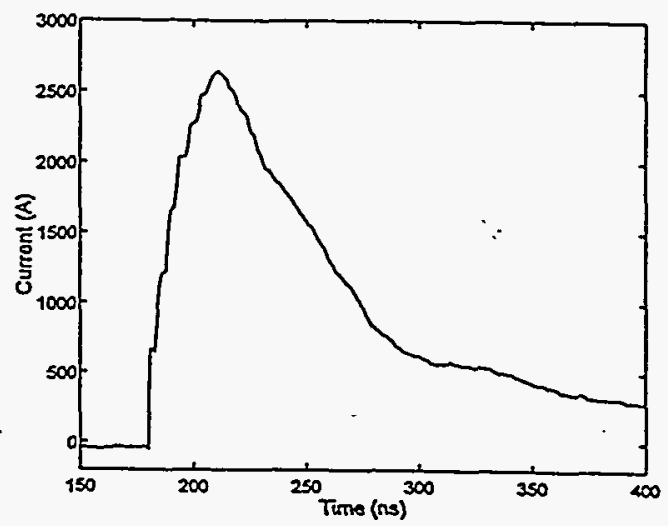

Figure 6. The current waveform for a capacitor dc charged at $3 \mathrm{kV}$. We used a $0.5 \mathrm{~mm}$ long by $2.5 \mathrm{~mm}$ wide $\mathrm{p}-\mathrm{i}-\mathrm{n}$ switch triggered with a fiber optic coupled laser diode arráy at $808 \mathrm{~nm}(1.6 \mu \mathrm{J})$. The peak current is $2.7 \mathrm{kA}$, the risetime is $21 \mathrm{~ns}$.

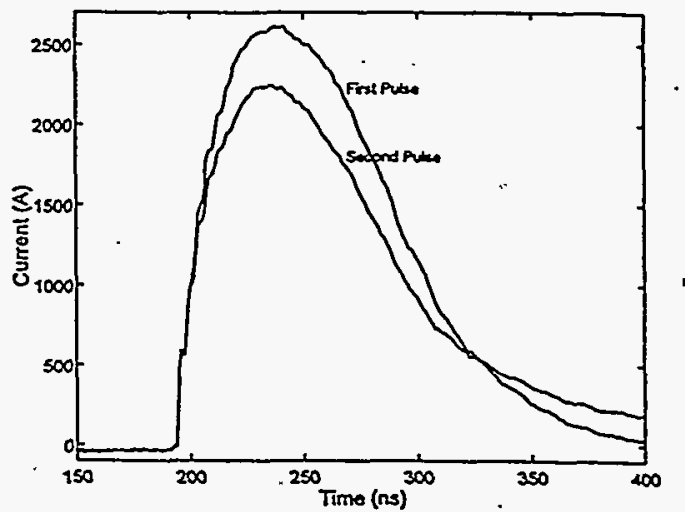

Figure 8. Current waveforms showing two pulses on the same switch. This was a $1 \mathrm{~mm}$ by $5 \mathrm{~mm}$ p-i-n switch triggered with the fiber optic coupled laser (808 $\mathrm{nm}, 1.6 \mu \mathrm{J})$. Peak currents are $2.65 \mathrm{kA}$ and $2.3 \mathrm{kA}$. 


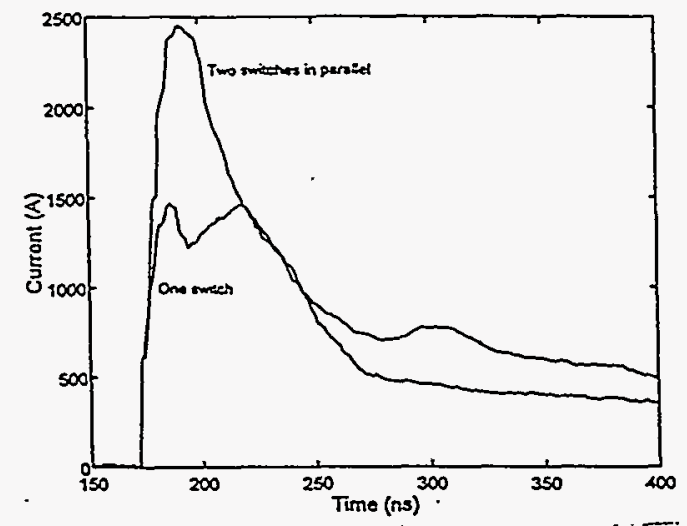

Figure 9. Current waveforms for one switch and for two switches in parallel. The switches were all $0.5 \mathrm{~mm}$ by 1 $\mathrm{mm}$ wide $(p-i-n)$ and triggered with the fiber optic coupled laser $(808 \mathrm{~nm}, 1.6 \mu \mathrm{J})$. Peak currents are 1.47 $\mathrm{kA}$ (for 1 switch) and $2.44 \mathrm{kA}$ (for 2 in parallel).

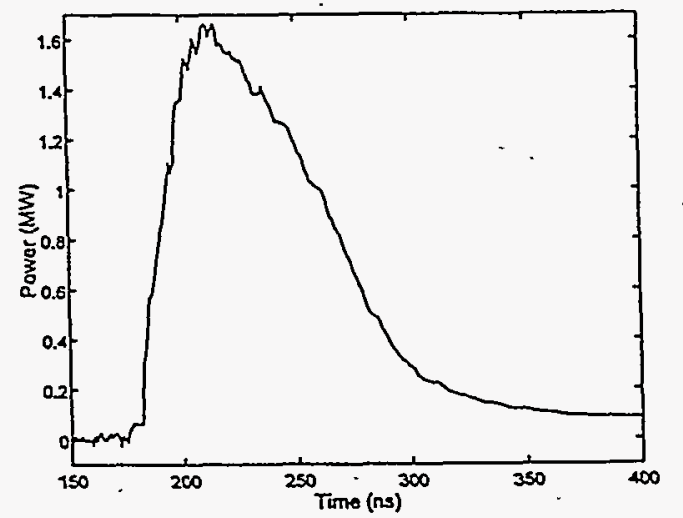

Figure 11. The power on the switch for the same pulse described in figures 3 and 10 . The energy deposited on the switch is $120 \mathrm{~mJ}$ out of an initial $540 \mathrm{~mJ}$ on the canacitor

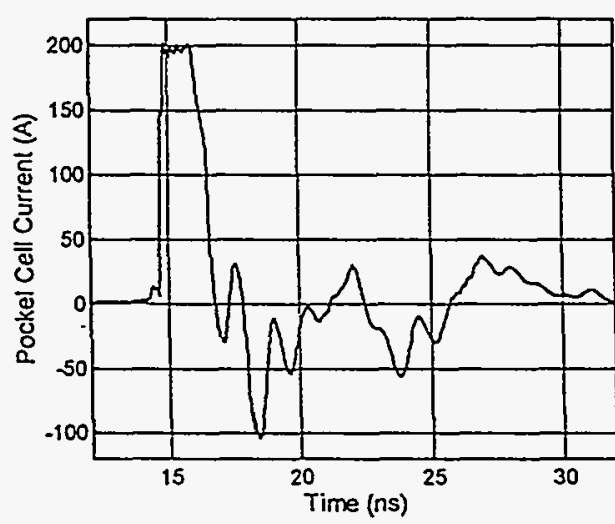

Figure 13. Current waveform for Pockels cell experiment. The peak current is about $200 \mathrm{~A}$ and lasts for about 2 ns.

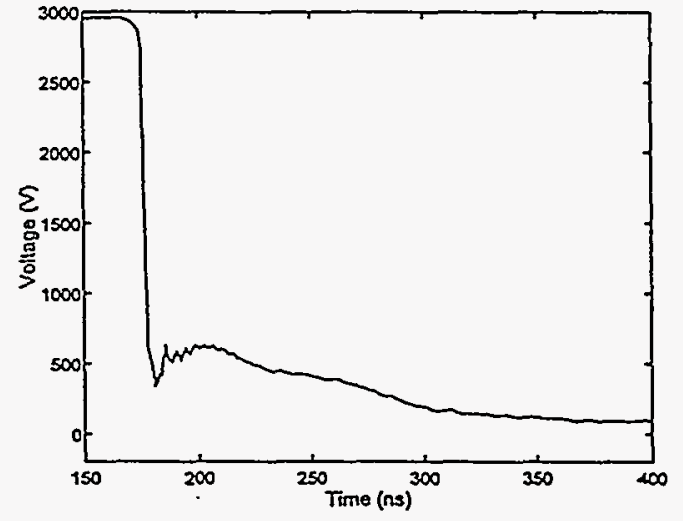

Figure 10. The voltage across the switch for the same pulse described in figure 3 . Note that the voltage drops to close to $300 \mathrm{~V}$ and does not remain constant.

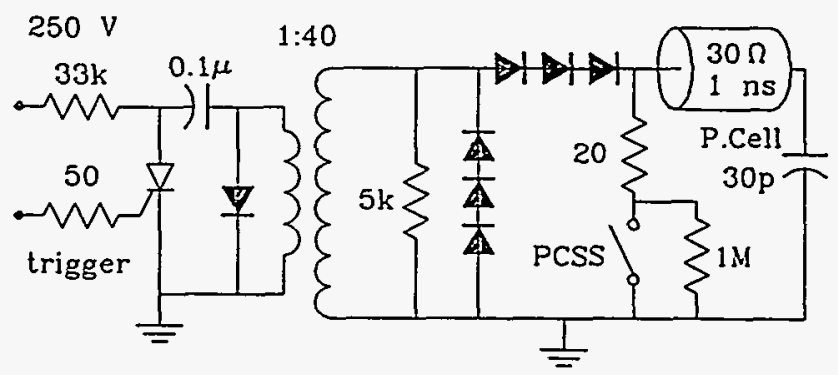

Figure 12. Circuit for Pockels cell experiment. The Pockels cell is pulsed charged to $6 \mathrm{kV}$ and discharged through the switch. The voltage pulse duration is a few $\mu$ s. The diodes allow the Pockels cell to remain charged for longer times. The $20 \Omega$ resistor and the switch resistance must match the transmission line impedance to avoid voltage reflections that cause ringing.

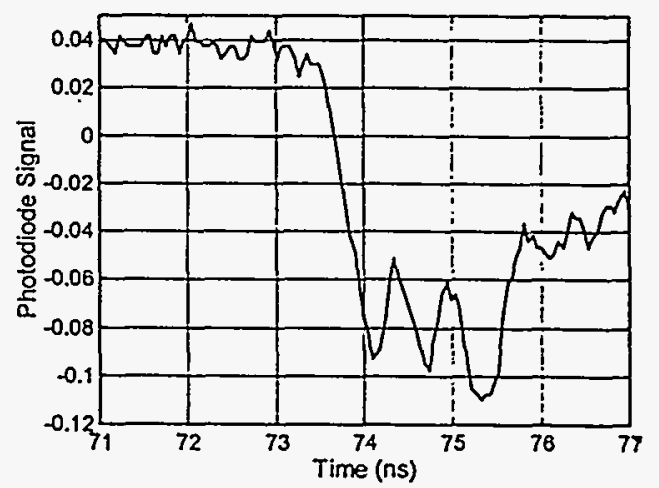

Figure 14. Optical waveform with Pockels cell switching. The falltime is about $600 \mathrm{ps.} \mathrm{The} \mathrm{noise}$ after switching is due to mode beating in the laser and does not represent noise in the Pockels cell. 